\title{
DOS GABINETES DE CURIOSIDADE AOS MUSEUS COMUNITÁRIOS: A CONSTRUÇÃO DE UMA CONCEÇÃO MUSEAL À SERVIÇO DA TRANSFORMAÇÃO SOCIAL
}

\author{
Moana Campos Soto ${ }^{1}$
}

\section{Resumo}

Ao longo do tempo múltiplas concepções de museus se desenvolveram, dos velhos gabinetes de curiosidade aos museus públicos surgidos no contexto pós-Revolução Francesa, criados para construir a identidade nacional e 'iluminar as massas'. Contudo, o surgimento de uma nova concepção museal, como uma instituição construída pela participação comunitária e a serviço da transformação social é recente, da segunda metade do século XX. Este artigo pretende apresentar o contexto de gestação e o desenvolvimento deste pela Nova Museologia. Para isso, principia mostrando a evolução dos museus até a Segunda Guerra Mundial. Depois, avança apresentando as entidades no âmbito das quais surgiriam essa nova concepção: a UNESCO, o ICOM e o ICOMOS. E, por fim, centra-se no MINOM e no desenvolvimento de suas novas idéias através de seus fóruns e resoluções, apresentando uma visão geral das mesmas.

Palavras-chave: MINOM, ICOM, ICOMOS, Museu, Nova Museologia.

\section{Abstract}

Over time many have developed conceptions of museums, the old cabinets of curiosity to the public museums emerged in the post-French Revolution, designed to build national identity and 'enlighten the masses'.

1 Pedagoga, Museóloga e Mestre em Museologia pela Universidade Lusófona de Humanidades e Tecnologias de Lisboa. Integrante da Seção de Museologia do Museu Nacional/UFRJ (Brasil).

moanasoto@gmail.com 
However, the emergence of a new design museum asan institution built by the community participation and for social change is recent, the second half of the twentieth century. This article aims to present the context of pregnancy and the development of the New Museology. For that, it starts showing the evolution ofmuseums until the Second World War. Then, presenting the advances entities within which arise the new design: UNESCO, ICOM and ICOMOS. And, finally, focuses on MINOM and developing their new ideas through their forums and resolutions, providing anoverview of them.

Keywords: MINOM; ICOM; ICOMOS; Museums; New Museology

\section{Introdução}

A palavra museu é de origem grega (Mouseion), utilizada para designar o templo das musas que era também um local onde os cidadãos se exercitavam na poesia e música, além de um espaço consagrado aos estudos.

Na Antiguidade, já se encontravam coleções de objetos de arte ou de materiais raros ou preciosos, conforme registros de Homero (Séc. IX a.C.) a Plutarco (Séc. I e II d.C.). Na Grécia Antiga, era hábito construírem-se, ao lado dos templos, pequenos edifícios, necessários à guarda das oferendas (troféus, esculturas e trabalhos de arte). Na Idade Média, o hábito de reunir obras de arte era demonstração de prestígio para a elite feudal.

Durante a época das grandes explorações e descobrimentos dos século XVI e século XVII, se colecionavam uma multiplicidade de objetos raros ou estranhos dos três reinos considerados pela biologia na época: animalia, vegetalia e mineralia; além daqueles que eram produtos do trabalho humano. Apareceram desta forma, durante o Renascimento na Europa, as grandes coleções, reunidas desde os séculos passados, e constituídas pelas mais variadas peças, surgindo os chamados Gabinetes de Curiosidades ou Câmaras de Maravilhas, aonde diferentes objetos eram reunidos sob o sentido da acumulação. Em geral, nestes eram expostos curiosidades e achados procedentes de novas explorações ou instrumentos tecnicamente avançados.

Os gabinetes de curiosidades são os antecessores diretos dos 
museus. Tiveram um papel fundamental para o desenvolvimento da ciência moderna, embora refletissem a opinião popular do tempo. A edição de catálogos, geralmente ilustrados, permitia o acesso e a difusão de conteúdo para os cientistas da época. Mais voltados para o estudo das ciências naturais, os Gabinetes de Curiosidades estimularam algumas instituições públicas de ensino a constituírem suas próprias coleções científicas. Será, a partir do século XVII, que surgirá a necessidade de se organizar cientificamente essas coleções expostas nos Gabinetes agora já tidos como museus.

A criação do museu moderno ocorre entre os Séc. XVII e XVIII, a partir das doações de coleções particulares às cidades: doação dos Grimani à Veneza; dos Crespi à Bolonha; e, dos Maffei à Verona. Mas, o primeiro museu tal como é entendido hoje, surge a partir da doação da coleção de John Tradescant, feita por Elias Ashmole, à Universidade de Oxford, quando então é criado o Ashmolean Museum (1683). O segundo museu público foi criado em 1759, por votação do Parlamento inglês, que decidiu comprar a coleção de Hans Sloane (1660-1753), dando origem ao Museu Britânico.

O avanço do conhecimento, a influência dos enciclopedistas franceses e os aumentos da democratização da sociedade provocados pela Revolução Francesa fizeram surgir o conceito de coleção como instituição pública, chamado museu. O primeiro museu público só foi criado, em França, durante o governo revolucionário (Robespierre), em 1793: o Musée du Louvre.

Os humanistas resgataram a palavra museu de sua origem na Antiguidade. Nos dias de hoje os museus apresentam certas características que remontam ao Humanismo: a questão da coleta e da preservação dos acervos e a valorização dos vestígios deixados por culturas ancestrais - em relação ao século $\mathrm{XVI}$, a cultura Clássica - são considerados os fatores centrais do trabalho na esfera museológica.

Os princípios humanistas deste período contribuíram no desenvolvimento de uma concepção de colecionismo que, além 
do valor hedonistíco e econômico dos acervos, também reconhecia o seu valor formativo e/ou científico. No contexto do lluminismo pode-se reconhecer os fatores que impulsionaram o surgimento dos museus contemporâneos. Uma das características do período iluminista, se trata da busca por explicações das mais variadas questões do mundo, em especial aspectos relacionados às pesquisas em ciências naturais.

A chamada cultura da curiosidade vai sendo substituída por uma atitude mais contextualizada e especializada, que valoriza a busca pelo conhecimento através do estudo das coleções, dos objetos museais. A partir daí começam a surgir as divisões do acervo, as obras passam a ser classificadas e dessa divisão teremos a origem dos museus especializados, nesse momento, especificamente, temos os museus de belas-artes e os ciências naturais.

A emergência dos Estados nacionais europeus, já no século XVIII, impulsionou o desenvolvimento e a consagração definitiva dos museus. A necessidade de se constituir uma identidade nacional, por meio do patrimônio como herança coletiva da nação, surge como um dos alicerces fundamentais para a legitimação dos novos Estados.

A idéia de um museu a serviço do público, financiado e administrado pelo Estado, é a expressão máxima do espírito iluminista. O reconhecimento da importância, do valor da educação pública e universal difundiu a ideia de que as coleções, que anteriormente eram fonte de instrução e prazer de poucos, deveria ser acessível à todos.

O século XIX é um período em que surgem muitos dos mais importantes museus de todo o mundo. São coleções particulares que se tornam públicas: Museu do Prado (Espanha), Museu Mauritshuis (Holanda). Também nessa época surge o primeiro museu histórico - todo organizado em ordem cronológica - na Dinamarca (1830), e começam a surgir os museus de folclore: Dinamarca (1807), Noruega (1828) e Finlândia (1894).

Foi recentemente, no final do século $X X$, que a noção que 
distingue os patrimônios caiu, dando lugar a uma unicidade marcada, e não mais o "patrimônio total". Foi quando as ciências e a sociedade compreenderam que a história, ligada aos testemunhos humanos e animais, está efetivamente ligada ao meio, à natureza. Logo, liga-se a uma ecologia onde não mais se mostra apenas a selva, mas o meio transformado pelo Homem, como a cidade que deu lugar à área desmatada. Passa-se a mostrar o ambiente humanizado, em que a humanidade constrói o seu modo de produção: seja no plantio, seja na criação, e que, através desse modo cultural enfrenta as adversidades.

Com isso, a economia, a sociologia, a história, a cultura, se destacaram e vêm se destacando no ecossistema, 'capacitador' das criações, das conquistas e, infelizmente, derrotas humanas. Daí um patrimônio total que, mesmo intocável, é fonte de riqueza e de possíveis atos ilícitos do Homem, sendo portanto cultural.

Seguindo essa nova concepção do patrimônio, instituições e organizações de grande credibilidade internacional como a UNESCO, o ICOM e o ICOMOS, produziram, nos últimos cinquenta anos, um conjunto de documentos sobre museologia e patrimônio que influenciaram a prática museológica atual. Estes documentos levaram a elaboração de vários outros e modificaram conceitos e leis visando uma nova política cultural.

Para entender essa nova orientação, buscar-se-á estudá-la utilizando-se de alguns documentos produzidos em reuniões realizadas com o apoio do Conselho Internacional de Museologia (ICOM). Para isso, apontar-se-á a importância de cada um destes para a evolução do conceito e da prática da museologia. Os documentos são os produzidos no Seminário Regional da UNESCO sobre a Função Educativa dos Museus, ocorrido no Rio de Janeiro no ano de 1958; na Mesa Redonda de Santiago do Chile, em 1972; no I Atelier Internacional da Nova Museologia, na cidade de Quebec no Canadá, realizado em 1984; na Reunião de Oaxtepec, ocorrida no México em 1984; e, na Reunião de Caracas na Venezuela, em 1992. Também se abordarão os 
documentos produzidos no âmbito do Conselho Internacional de Monumentos e Sítios (ICOMOS).

1 - As novas concepções museológicas e as novas organizações do pós-Segunda Guerra Mundial ${ }^{1}$

A UNESCO (Organização das Nações Unidas para a Educação, Ciência e Cultura) foi criada em 1945, pela ONU, como instituição especializada. Seu objetivo é, através da cultura, ciência e educação estreitar a colaboração entre as Nações com vistas a assegurar o respeito à justiça, às leis, aos direitos do homem e às liberdades fundamentais, desta maneira garantindo-se a manutenção da paz e da segurança mundial. Esta organização parte do princípio que o desenvolvimento desses três elementos (cultura, ciência e educação) permite uma melhor compreensão mútua entre os povos e, desta forma, a diminuição das tensões e incompreensões que estariam na base de muitos conflitos.

No âmbito das suas atribuições a UNESCO recebe a contribuição de Organizações criadas no seio da própria UNESCO, sendo necessário destacar, por tratarem especificamente de questões museológicas e de patrimônio o ICOM e o ICOMOS.

\section{1 - Conselho Internacional de Museus (ICOM)}

O ICOM (Conselho Internacional de Museus), criado em novembro de 1946, é uma Organização não Governamental de museus e de seus profissionais, que visa trabalhar na promoção dos interesses da Museologia e de outras disciplinas relacionadas às atividades dos museus.

Os objetivos do ICOM estabelecem o seu compromisso com: o apoio à criação e desenvolvimento de todos os museus, seja qual for a sua tipologia, auxiliando na organização e cooperação entre estes museus e profissionais, seja em âmbito nacional como internacional; a divulgação e, por consequência, o desenvolvimento do campo da Museologia, bem como de outras disciplinas afins; além de representar os interesses de todos os membros da profissão museológica.

A relação museu-sociedade também é um dos focos de atenção 
do ICOM, em seus objetivos fica claro também que é seu papel trabalhar para o melhor conhecimento do lugar que os museus ocupam na sociedade, percebendo a sua função e, como as instituições, cada uma em seu modo particular, podem colaborar para o desenvolvimento social.

O conceito de museu mudou muito nos últimos anos, no artigo $2 \S 1$ dos Estatutos do Conselho Internacional de Museu é definido como:

"instituição sem fins lucrativos, permanente, a serviço da sociedade e de seu desenvolvimento, e aberta ao público, que adquire, conserva, pesquisa, divulga e expõe, para fins de estudo, educação e divertimento, testemunhos materiais do povo e seu meio ambiente." "Um museu, por definição, é uma instituição a serviço da sociedade e de seu desenvolvimento, e geralmente é aberta ao público (mesmo que este público possa ser restrito, no caso de certos museus muito especializados, como certos museus acadêmicos ou médicos, por exemplo)".

O ICOM propõe que o museu deve aproveitar todas as oportunidades para desenvolver o seu papel de recurso educativo a ser usado por todos os setores da população ou por grupos especializados, aos quais ele tem por objetivo servir. Deve atrair audiências novas e mais amplas dentre as camadas da comunidade, localidade ou grupo ao qual tem por objetivo servir, e deve oferecer a ambos, tanto a comunidade em geral como a indivíduos ou grupos específicos, oportunidades de envolvimento ativo em prol de objetivos e políticas.

No mesmo Estatuto nomeiam então as instituições designadas como "museus":

- Monumentos e sítios naturais arqueológicos e etnográficos de natureza museal que adquirem, conservam e divulgam evidências materiais do povo e seu meio ambiente;

- Instituições que mantém coleções de espécimes vivos de plantas e animais, e que expõem, como jardins botânicos e zoológicos, aquários e viveiros;

- $\quad$ Centros científicos e planetários; 
- Institutos de conservação e salas de exposição mantida permanentemente por bibliotecas e arquivos históricos;

- $\quad$ Reservas naturais;

- $\quad$ Outras instituições que possuam algumas ou todas as características de um museu, ou de apoio a museus ou profissionais de museus através de pesquisa, educação ou treinamento museológico.

Deve-se lembrar que a institucionalização dos museus no Brasil antecede ao conceito do ICOM e que as noções e as práticas de preservação e uso educacional do que viria a ser chamado de patrimônio cultural surgiram antes no campo dos museus.

\section{2 - Conselho Internacional de Monumentos e Sítios (ICOMOS)}

O ICOMOS (Conselho Internacional de Monumentos e Sítios) foi criado a partir das recomendações oriundas da Carta de Veneza, resultante do II Congresso de Arquitetos e Técnicos de Monumentos Históricos, realizado em 1934. O ICOMOS se configura enquanto uma organização não governamental internacional que atua na promoção da conservação, proteção, reabilitação e melhoria de monumentos, grupos de edifícios e sítios, tanto no âmbito nacional quanto internacional.

O ICOMOS tem o papel fundamental de estreitar as relações de colaboração entre as mesmas, bem como junto ao International Centre of Study of the Preservation and Restoration of Cultural Property (ICCROM) e outros centros regionais de conservação também patrocinados pela UNESCO, além de todo e qualquer grupo nacional ou internacional que também atue por objetivos equivalentes.

Estas relações tornam possível a cooperação na preparação de programas de treinamento dos profissionais, voltados para a formação de especialistas em conservação, proteção e melhoria de monumentos, sítios e grupos de edificações em geral, promovendo assim a ligação entre instituições, autoridades públicas e indivíduos que, preocupados com a conservação destes, possam ter assegurado sua representação diante das 
grandes organizações internacionais.

Assim como o ICOM, o ICOMOS deve apoiar a criação e desenvolvimento de centros de documentação ligados à proteção, conservação e melhoria de monumentos, sítios e grupos de edificações, voltados também para a divulgação e estudo de conhecimentos referentes aos princípios, técnicas e programas especializados.

Tanto o ICOMOS quanto o ICOM exercem um papel de grande importância junto à UNESCO em diversas áreas, principalmente no que se refere à elaboração das listagens do Patrimônio Cultural Mundial (material e imaterial; tangível e intangível).

\section{2 - As novas concepções museológicas}

Antes mesmo do surgimento dessas novas organizações, no período compreendido entre as décadas de 20 e 30, marcado pela necessidade de se constituir uma identidade nacional, por meio do patrimônio como herança coletiva da nação e, com o reconhecimento da importância, do valor, da educação pública e universal difundiu-se de forma mais generalizada a ideia de que as coleções, anteriormente fonte de instrução e prazer de poucos, deveriam ser acessíveis à todos, e caberia às elites dinamizar as questões político-culturais, o que incluía a esfera museológica.

As revoluções comportamentais e tecnológicas acontecidas durante a década de 50 , tais como o desenvolvimento e massificação do cinema e a descoberta do DNA, o conflito entre a União das Repúblicas Socialistas Soviéticas (URSS) e os Estados Unidos da América (EUA), a chamada Guerra Fria; e o início dos movimentos de descolonização na África e na Ásia, serviram de pano de fundo para a produção de documentos que visavam desenvolver as práticas no âmbito da Museologia e dos museus. Ao se tratar da elaboração documental neste período, deve-se destacar, em 1958, o Seminário da Unesco sobre a função educativa dos museus, em que se estabeleceu uma nova visão 
tanto para os objetos museológicos, bem como o caráter educativo que deve ter o museu.

"O museu pode trazer muitos benefícios à educação. Esta importância não deixa de crescer. Trata-se de dar à função educativa toda a importância que merece, sem diminuir o nível da instituição, nem colocar em perigo o cumprimento das outras finalidades não menos essenciais: conservação física, investigação científica, deleite, etc".

A partir de então, os museus se consolidaram enquanto espaços públicos à serviço do público, e cada vez mais a noção de coleção foi sendo substituída pela de patrimônio. Os grandes museus, das maiores e mais importantes capitais européias, já estavam constituídos. Contudo, as suas coleções agora tinham novas dimensões, que indo além da mera apreciação, se tornavam cada vez mais instrumentos de educação e objetos da investigação científica.

As propostas nessa área sugeriam a separação entre as coleções voltadas para a pesquisa científica e as de instrução do chamado público leigo.

Todas coleções museológicas se constituem através de escolhas, e a natureza desta decisão em muito está relacionada às suas finalidades, seus objetivos. A transformação dos museus em espaços públicos vinculados ao Estado lhes confere novos objetivos em relação ao público, e por conseqüência, novos referenciais de escolha na constituição e para a exposição de suas coleções.

Os museus perceberam que se faz necessária uma política de aquisição coerente de suas coleções. As escolhas na aquisição não devem se dar em função do gosto dos curadores ou pela raridade e valor de suas obras, mas sim a partir de critérios bem definidos de acordo com objetivos estabelecidos previamente, buscando também ir de encontro as necessidade do público, seja este leigo ou especializado.

Durante as décadas de 60 e 70 se processou o alargamento da noção de determinados termos no campo da Museologia, o 
conceito clássico de museu - que operava com as noções de edifício, coleção e público - foi confrontado com novos conceitos, novas abordagens, que ampliavam e problematizavam o que era antes, de certa forma, estigmatizado socialmente.

Passou a se operar através de novas categorias: o território (socialmente praticado), o patrimônio (socialmente construído) e a comunidade (construída por laços de pertencimento).

No Chile, em 1972, se complementou o conceito de museu e suas ações, a instituição passou a ser entendida como instrumento de mudança social, para o desenvolvimento e, suas ações devem ser direcionadas para proporcionar à comunidade uma visão em que se estabeleça o quadro histórico e a reflexão sobre os problemas atuais.

2.1 - O surgimento do Movimento Internacional para uma Nova Museologia (MINOM)

As transformações operadas no pós-Segunda Guerra Mundial, com a emergência do bloco socialista (antes reduzido à URSS e Mongólia) e a concorrência de projetos sistêmicos surge uma nova conjuntura internacional. Há um crescente descontentamento em vários setores da sociedade, em especial na Europa, que depois se estende à praticamente todo o mundo. A partir dos anos sessenta, este quadro se torna ainda mais fértil para o surgimento de uma série de movimentos que se desenvolveram nos campos social, político e cultural, como por exemplo, o maio francês.

Nesse momento histórico, os intelectuais da área museológica também estiveram presentes, contribuindo para a mudança social através da democratização da cultura. Essa renovação de ideias no âmbito dos museus - repensando a noção tradicional de patrimônio; afirmando a responsabilidade social do museu e colocando a Museologia como agente da mudança - é fator fundamental para se compreender o que é o Movimento Internacional para uma Nova Museologia (MINOM) e o porquê da sua importância até os dias de hoje. 
A história do MINOM se inicia efetivamente no pós-guerra, quando se consolida a ONU (Organização das Nações Unidas), uma estrutura que vai dar origem, como já dito acima, ao mais importante organismo a cerca das questões culturais no mundo: a UNESCO. Tendo em vista o âmbito dos museus e do patrimônio, esta criou o ICOM, que foi organizado em comitês. O ICOM, primeiro sob a orientação de Georges-Henri Rivière e, mais tarde, tendo Hugues de Varine como diretor, decidiu reunir os profissionais de museus em encontros e conferências mundo a fora, com vistas à facilitar a reflexão e tomada de decisões em temas fundamentais para a Museologia mundial. Com o apoio da UNESCO, a partir da década de 60, esses fóruns vão propiciar as discussões que posteriormente serão a base para o desenvolvimento da chamada Nova Museologia.

Esses encontros, primeiramente, tornaram visível a mentalidade conservadora de muitos profissionais ligados a área museológica, bem como do poder político ligado à cultura. $\mathrm{O}$ quadro dos grandes museus mundiais, em particular na Europa e América do Norte, apontava para duas tipologias: o museu "clássico", com uma estrutura piramidal, na qual se encontra no topo a figura do grande conservador, abaixo a grande exposição permanente, seguida por outras exposições menores e temporárias e, na base, os serviços (pesquisa, educativo, etc.); com a explosão do turismo de massas, surge a chamada "fábrica da cultura", um museu que, também de estrutura piramidal, traz no topo o diretor da instituição, seguido de uma equipe de profissionais das mais diversas áreas (incluindo os serviços, a destacar o marketing voltado para atração de público), abaixo as mais diversas exposições temporárias e, na base, a coleção permanente, que tende a servir às outras exposições externas (oriundas de empresas especializadas em grandes exposições). Indo contra essas duas visões do trabalho e papel dos museus, estavam os museus etnográficos e de história local que apontavam para a conservação de espaços territoriais, mas ainda assim uma realidade concebida a partir do discurso 
intelectualizado e muito distante da realidade comunitária. Contudo, através desses contributos, o campo da Museologia irá desenvolver uma série de orientações e reflexões que serão base fundamental para o nascimento dos Ecomuseus e do próprio MINOM.

Já existiam algumas experiências que se aproximavam deste conceito: os museus cantonais, em França, já se preocupavam com os bens patrimoniais históricos e artesanais, bem como as populações trabalhadoras (1876); no Reino-Unido, o Outlook Tower apresentava um novo museu local, que ia além da conservação da tradição ao integrar o presente, ao considerar tanto o entorno como a própria comunidade como acervo (1892); os Vagões de Exposição criados na antiga União Soviética, que tinham como objetivo principal a educação popular e a divulgação de uma nova identidade nacional (1917); e, esse conceito de utilidade do museu para a comunidade propicia também, nos Estados Unidos, a criação de espaços para a afirmação das identidades, os chamados Neighborhood Museum (1967); por fim, vale destacar o México, onde o arquiteto Mário Vázquez cria a Casa Del Museo que tinha como objetivo a conscientização e formação das populações locais (1968).

Contudo, a grande inspiração de Georges-Henri Riviére foram os museus de Skansen, na Suécia, e de Arnheim, nos Países Baixos, exemplos de museus ao ar livre que, em fins do século XIX, reproduziam territórios escolhidos para melhor exemplificar a vida das comunidades.

As primeiras experiências verdadeiramente comunitárias iriam surgir em França, na cidade de Le Creusot e, dois anos mais tarde, em 1973, Riviére iria definir formalmente o que é realmente um Ecomuseu. O pioneirismo da França é facilmente explicado ao se considerar que o ICOM, desde de sua criação, sempre esteve a desenvolver grande parte de sua atividade neste país, através da atuação de personalidades francesas em que se destacaram o próprio Riviére e Hugues de Varine, que 
através de suas ideias dinamizaram as discussões acerca do que hoje se entende por Nova Museologia.

Surge então o primeiro Ecomuseu, um dos marcos do ano de 1971, no entanto não seria esse o único. O clima de renovação no âmbito da Museologia fez surgir uma série de publicações que denunciavam o espírito por demais conservador dos profissionais de museus e a imobilidade da própria Museologia enquanto campo diante das necessidades de atuais. A partir daí foram também apresentadas propostas alternativas visando a tão desejada renovação museológica. Em setembro do mesmo ano, o ICOM realiza em Grenoble sua IX Conferência aonde foi redefinido o conceito de museu, afirmando a sua dimensão política e de valorização do meio ambiente.

Ainda nessa mesma conferência, o termo Ecomuseu foi apresentado e passou a ser então oficialmente utilizado para definir a instituição que, para além das características de museu ao ar livre, também tem todo um envolvimento comunitário e, sendo assim, a partir de então foi reconhecido pelo poder político.

Voltados ao desenvolvimento social e para operar com todo um acervo de problemas que afetam indivíduos e grupos a eles ligados, os chamados Ecomuseus apontam para uma concepção museológica segundo a qual o museu torna-se um veículo de educação e comunicação, integrado ao desenvolvimento da comunidade. Alguns museus surgidos ou transformados com base nessas propostas passaram a considerar suas coleções como um "meio" para a realização de trabalhos de interesse social; suas intervenções ampliaram-se e orientaram-se para a valorização da localidade, o fomento do emprego e as áreas de comunicação e educação.

O museu vai até o público, trabalha junto dele, é participante da vida de uma coletividade. Os projetos são também das comunidades que desenvolvem as concepções que valorizam o patrimônio cultural, sistematizam o turismo cultural local, preservam a memória social e contribuem para a economia. 
O esforço para sistematizar as novas experiências museológicas e marcar as diferenças com outros referenciais teóricos levou o teórico Hugues de Varine a estabelecer o seguinte quadro esquemático:

Museu tradicional = edifício + coleção + público

Ecomuseu/Museu Novo = território + patrimônio + população No museu clássico existe o objeto e a coleção, enquanto que na Nova Museologia são considerados todos os bens culturais de um território, de uma região.

Pode-se destacar, nos marcos desta nova definição, após a Mesa Redonda de Santiago do Chile (1972), o Museu Nacional de Antropologia do Instituto Nacional de Antropologia e História do México quando lançou o Projeto experimental a Casa del Museo, em três áreas populares: Zona do Observatório, El Pedregal de Santo Domingo e Nezahualcoytl. A prática nessas áreas apontou para uma concepção museológica, segundo a qual o museu passava a ser um veículo de comunicação integrado ao desenvolvimento da comunidade.

$\mathrm{O}$ conceito de patrimônio também foi redefinido. Ao se realizar uma operação de passagem do conceito de coleção para o de patrimônio, os problemas foram ampliados. No entanto, as práticas ecomuseológicas também aqui não parecem, em muitos casos, reforçar a idéia de coleção ou mesmo de patrimônio, concebido como um conjunto de bens culturais. Práticas museológicas como as do Museu Didático-Comunitário de Itapuã (BA); do Ecomuseu de Santa Cruz (RJ) ou do Museu Etnológico de Monte Redondo (Portugal) operam com o acervo dos indivíduos envolvidos com os processos museais. Nos três casos, não há a preocupação patrimonial no sentido exclusivo de proteção do passado, mas sim um interesse na dinâmica da vida. Em outros termos: o interesse no patrimônio não se justifica pelo vínculo com o passado, seja ele qual for, mas sim pela sua conexão com os problemas fragmentados da atualidade e com vistas à transformação futura.

A Mesa Redonda de Santiago do Chile, promovida pelo ICOM e 
UNESCO, marcou as discussões no âmbito da América Latina e, principalmente, por ter sido o cenário da produção de uma declaração fundamental para o desenvolvimento da Nova Museologia.

O ano de 1983 foi marcado pelo nascimento de um dos movimentos que mais dinamizaria a doutrina da Nova Museologia. Apesar de seu curto período de existência, o Muséologie Nouvelle et Expérimentation Sociale (MNES) conseguiu reunir uma série de intelectuais do meio museológico, com o intuito de produzir Boletins periódicos que pudessem divulgar as idéias da Nova Museologia pelo mundo.

Durante a XII Conferência Geral do ICOM, em 1983, uma parte dos membros fez uma analise crítica da imobilidade dos órgãos tradicionais no campo da Museologia e apontaram sua falta de comprometimento com as questões das minorias. Esse grupo se reuniu com outros intelectuais ligados aos museus para organização de um colóquio no Canadá que seria o ponto de partida para a criação do MINOM.

As discussões acerca da organização do colóquio possibilitaram a construção e consolidação dos referenciais e objetivos que, no I Atelier Internacional Ecomuseus / Nova Museologia, culminaram no nascimento oficial do MINOM. Assim, a partir de 1984, o movimento da Nova Museologia e dos Ecomuseus era reconhecido através de um organismo próprio. Outro aspecto fundamental deste primeiro Atelier que merece ser destacado é a produção da Declaração de Quebec, documento referencial para as estruturas do próprio MINOM.

A partir de então ficavam claras as aptidões necessárias para se integrar a este movimento, através do conhecimento e reconhecimento das práticas museológicas de cada instituição diante dos posicionamentos da Declaração de Quebec. Ou seja, diante da criação do MINOM, cabe a cada museu descobrir o que é a chamada Nova Museologia e perceber se há um encontro de ideias e práticas com esse movimento.

A Nova Museologia é o resultado de uma reflexão do fazer e 
pensar tradicionalista dos museus. Através de novas experiências e considerando o que era anteriormente excluído, este movimento criou uma Museologia da libertação, que abre espaço para a criação, a consciência crítica e a participação ativa da comunidade. O museu que, anteriormente, se tratava de um espaço, instituição com objetivos e funções definidas pelo ICOM, agora vai além e também se torna um processo, que visa "contribuir para a transformação de uma realidade não dominada pela comunidade num recurso útil para seu desenvolvimento, tanto presente quanto futuro". (Varine, 2000).

"O museu é uma instituição a serviço da sociedade, da qual é parte integrante e que possui nele mesmo os elementos que lhe permitem participar na formação da consciência das comunidades que ele serve; que ele pode contribuir para o engajamento destas comunidades na ação, situando suas atividades em um quadro histórico que permita esclarecer os problemas atuais, isto é, ligando o passado ao presente, engajando-se nas mudanças de estrutura em curso e provocando outras mudanças no interior de suas respectivas realidades nacionais". (ICOM, 1872)

O fim da Guerra Fria e a queda do muro de Berlim, impulsionaram o crescimento do capitalismo mundo a fora, a partir dos anos 80. Daí a lógica comercial dominante dinamizou o potencial econômico e estratégico da cultura, tornando-a assim mais um bem passível de ser comercializado. A cultura sofre um processo de mercantilização. Por outro lado, neste mesmo período, a Nova Museologia ganha força através das ações impulsionadas por outros documentos produzidos, em especial, no ano de 1984.

A Declaração de Quebec, Canadá (1984), traz idéias a cerca das novas possibilidades do fazer museológico, e o reconhecimento do movimento da Nova Museologia, que viria a ser formalizado já no ano seguinte (1985), em Lisboa, durante o II Encontro Internacional - Nova Museologia / Museus Locais, sob a 
denominação de Movimento Internacional para uma Nova Museologia (MINOM).

Outro documento de 1984, no México, a Declaração de Oaxtepec, integra então a relação de território, patrimônio e comunidade, marcando definitivamente a importância da comunidade, para estabelecer a parceria efetiva entre museu e sociedade: "La participación comunitaria evita las dificultades de comunicación, característica del monólogo museográfico emprendido por el especialista, y recoge las tradiciones y la memoria colectivas, ubicándolas el lado del conocimento científico." (Declaração de Oaxtepec, México, 1984).

A mesma declaração também defende a preservação in situ e justifica tal ideia com o argumento de que, ao se retirar um patrimônio de seu contexto, modifica-se a ideia original. A defesa da preservação in situ deve-se ao fato da consideração do espaço territorial como área museográfica. Fortalece-se a ideia de patrimônio cultural, passando a entendê-lo através de uma visão integrada da realidade.

"A função museológica é, fundamentalmente, um processo de comunicação que explica e orienta as actividades específicas do museu, tais como a coleç̧ão, conservação e exibição do património cultural e natural. Isto significa que os museus não são somente fontes de informação ou instrumentos de educação, mas espaços e meios de comunicação que servem ao estabelecimento da interacção da comunidade com o processo $e$ com os produtos culturais" (ICOM, 1992).

Os anos 90 se iniciaram com a Declaração de Caracas (1992), Venezuela, que vinha analisar a situação dos museus latinos, define-se o Museu Integrado na Comunidade, tratando a reformulação das políticas de formação de coleções, conservação, investigação, educação e comunicação, tudo isso em função de se estabelecer uma relação com a comunidade.

2.2 - A Nova Museologia no século XXI

Como dito acima, ao longo do século $X X$, uma série de 
transformações, impulsionadas pelas orientações apresentadas nos documentos produzidos por organizações tais como UNESCO, ICOM e ICOMOS deram origem a Nova Museologia. Essa foi gerada através de novos conceitos e práticas nas instituições museológicas que deixaram de ter como preocupação única e exclusiva as questões administrativas, documentais e preservacionistas, para passarem a incluir as necessidades e anseios sociais, passando a utilizar uma visão de um patrimônio global. A política museística que anteriormente estava centrada no objeto muda de foco, tendo então o público, a comunidade, como ponto central de suas ações.

Os encontros promovidos pelo MINOM, denominados de 'Atelier', fazem parte de um

"trabalho sistemático de formação e divulgação dos princípios da Nova Museologia e da Museologia Social realizado desde o MINOM - Portugal, através da organização de suas Jornadas, dos Encontros de Museologia e Autarquias e do seu envolvimento nos Encontros de Museologia e Educação. Existe ainda uma forte reserva de reflexão teórica produzida nas Universidades, em que se ministra formação superior nestas áreas, fruto do trabalho de Museólogos e Historiadores que se dedicam à Museologia Participativa desde o nascimento do MINOM."(Stofftel, 2007).

As conferências e encontros no século XXI são marcadas pelas discussões em torno a influência das transformações mundiais na era da globalização no âmbito dos museus, das instituições nacionais e internacionais de foro museológico e/ou patrimonial e da própria Museologia enquanto ciência produtora de conhecimento.

3- Um novo quadro na museologia

Indo ao encontro dessa temática, pode-se definir um quadro acerca do resultado dessas transformações no cotidiano dos cidadãos e profissionais, da gestão e também dos conceitos relativos aos museus e a Museologia, apontando, além das 
dificuldades, algumas perspectivas para a melhoria das ações museológicas.

Diante do crescimento dos movimentos e expressões de identidades coletivas mundo a fora, mesmo sendo este globalizado e pensado a partir dos referenciais norte americanos, o Atelier do MINOM abre as discussões sobre o papel dos museus e da Museologia diante deste fenômeno.

Enquanto conceito fundamental para a prática museológica, a identidade se configura enquanto um fenômeno produzido social e individualmente, que se constrói referenciado aos outros, aos critérios de aceitabilidade e credibilidade, através de negociações diretas entre os atores sociais. As questões em torno da construção da identidade dos indivíduos, pertencentes aos diversos grupos sociais, se coloca hoje como um ponto central nas discussões da Nova Museologia. Para esta, pensar como o mundo globalizado trata as diferenças culturais é a base para se desenvolver ações que, através dos museus, possam viabilizar a tolerância e o respeito entre os povos, reforçando assim a tão necessária diversidade cultural mundial.

Os museus hoje só terão sucesso através de práticas sustentáveis, respeitando todas as culturas, o ambiente, a sociedade e com uma gestão econômica responsável. A sustentabilidade se configura como viabilizadora da própria comunidade, e não apenas como um diferencial competitivo dos museus, ou seja, a sustentabilidade é um requisito indispensável para a sobrevivência sistêmica.

A gestão para a sustentabilidade deixou de ser um mero modismo para se tornar uma prática referencial. Por meio desta, os museus têm, além da preocupação com sua viabilidade econômica, a responsabilidade com todos os agentes afetados por suas ações: seus colaboradores, funcionários, dirigentes, governo, e principalmente com a comunidade e o meio ambiente em que está inserido.

O MINOM promove a cooperação comunitária que permitiria o afloramento das identidades culturais adquirindo as mais 
variadas formas de conhecimento e estimulando a procura de outros contextos, ao invés de homogeneizar a cultura e os hábitos.

Ao mesmo tempo em que a utilização do espaço global incentiva os processos de contato entre culturas e os museus, também contribui para o surgimento de diversas formas de gestão locais, que muitas vezes resultam na construção de novas referências simbólicas ou mesmo da reelaboração de antigos processos. Nesse sentido, as identidades locais estão sendo reforçadas. A valorização dos referenciais locais, cobre de importância a sustentação de identidades que possibilitem às pessoas a referência ao seu lugar e grupo de pertencimento, contribuindo para que o museu possa tornar-se instrumento de desenvolvimento comunitário.

Esse interesse pela identidade, e consequentemente, pela tradição, se reflete na criação de lugares de memória, locais de rememoração que, enquanto representantes de mais diversas tradições, procuram enfatizar uma noção de continuidade, o passado e o presente se encontrando de maneira a construir a realidade do espaço museal.

A proposta do movimento visa realizar uma ligação com as comunidades locais promovendo uma gestão participativa, as expressões função social do museu, museologia social, museus promotores de desenvolvimentosão, atualmente, muito utilizadas no mundo da Museologia. Estas se configuram enquanto instrumentos úteis de envolvimento mais ativo na promoção, implementação e operacionalização do museu, visando a aplicação real do conceito de cidadania, em especial, junto àqueles que estão à margem da sociedade.

Nesse sentido, o MINOM enfatiza que o museu não pode mais ser visto como uma instituição estável, seu espaço se ampliou e se diversificou, o público se modificou tanto nos aspectos sociais como nos culturais. O museu deixa de ser uma instituição, um espaço onde estão preservadas algumas coleções, para tornarse, não apenas o resultado, mas um processo de representação 
do comportamento comunitário.

O museu deve ser a instituição comprometida com os aspectos do patrimônio, da educação e da sociedade. Não se trata apenas de assimilar novas técnicas e tecnologias, mas de estruturar políticas culturais, educacionais e administrativas. Os museus não serão mais definidos por suas funções e sim por seus propósitos. Enquanto as funções vinculam-se mais as atividades operacionais, os propósitos são calcados em valores e revelam a política cultural da instituição.

É preciso mudar o foco das funções para os propósitos. No entanto, não há como se discutir uma coisa sem a outra. As funções são universais e podem ser aplicadas a todos os museus. Já os propósitos ou finalidades têm que possuir um profundo vínculo com a sociedade.

Hoje percebe-se que a principal finalidade do museu é trazer algum benefício aos indivíduos, provocar transformações positivas em suas vidas, e não ser simplesmente uma espécie de casa de custódia para obras de arte ou um centro erudito que está aberto tão somente para aqueles tidos como intelectualizados e cultos. O museu é parte da comunidade e também é representante desta, portanto deve ser um espaço de todos, sendo que os setores devem compartilhar desta visão, assim a prática da Sociomuseologia será concretizada.

Com implementação da administração participativa nos museus ocorreria o fim da relação dominante versus dominado, que por tantos anos predomina dentro das instituições museológicas. $\mathrm{O}$ processo participativo seria assim o aprender, o modificar, o aperfeiçoar, o evoluir, o pensar e o agir coletivamente. Desta forma, se têm a inovação, a engenhosidade, a pró-atividade, fazendo com que objetivos comuns, que interessam a todos, se sobreponham aos interesses individuais. Os relacionamentos se fortaleceriam e a cooperação se tornaria imperiosa. Tudo isso decorrente da gestão participativa, ou seja, do engajamento de todos.

Neste novo contexto, os sujeitos de uma comunidade devem ser 
participantes, o que pode ser considerado uma evolução do processo de gestão dos museus. A matéria prima dessa forma de gestão está nas pessoas e os valores que estas carregam. Esta gestão participativa pressupõe envolvimento e busca incessante do consenso em torno de objetivos estipulados. A mudança na figura do líder e suas atribuições em consequência de uma nova visão estratégica. O líder de hoje também precisa ser diferente do líder de ontem.

A gestão participativa é, sem sombra de dúvida, incompatível com hierarquias. As pessoas são envolvidas, estimuladas e desejosas de contribuir, em um clima de confiança entre as partes e isso não significa a destruição dos centros de poder. Não se trata de promover a instalação do caos ou algo assim. O que muda, essencialmente, é a forma com que as coisas acontecem, é a promoção de um melhor ambiente e do estímulo em cada um dos envolvidos para que verdadeiramente participem e contribuam para as decisões.

A partir dos preceitos colocados pelo MINOM, pode-se dizer que os objetos, além de possuírem um valor histórico ou artístico, possuem um papel de grande valor, de acordo com o modo como eles se apresentam. Essa importância existe na relação destes com o público que visita esse espaço e que lhes confere um significado. É justamente nesse processo de comunicação entre público e o objeto que se poderá estabelecer uma relação com determinado fato, momento ou período - tradição - para uma dada comunidade. É através do museu que o público entra em contato com patrimônios e, a partir desta relação, constrói diferentes concepções a respeito tanto de questões pessoais quanto coletivas e que se referem a uma determinada realidade. Os gestores/diretores começam a perceberam a importância da gestão participativa, principalmente em relação às tomadas de decisões. Isto se dá, porque, através da democracia como instrumento de gestão, o setor ganha mais visibilidade e credibilidade na transparência das decisões, possibilitando assim seu crescimento e, como consequência, maior possibilidade de 
integração junto à comunidade, parcerias e recursos, fatores estes primordiais ao seu desenvolvimento.

O estabelecimento de ações sustentáveis e duradouras nos museus é uma meta para uma nova museologia na chamada era do conhecimento. Por trás desse conceito está a viabilidade econômica, numa ampla plataforma de tendências e organizações, utilizando instrumentos de desenvolvimento da sociedade e da satisfação de suas necessidades e visando a preservação de recursos sem inviabilizar o necessário às gerações futuras.

A implementação da proposta de gestão participativa tem como objetivo de integrar cada vez mais e dar uma maior credibilidade aos museus - enquanto espaço social de memória e identidade perante aos mais diversos grupos sociais. Nesse sentido, não se pode negar o papel que o museu ocupa hoje, tanto como um espaço de identidades, mas principalmente como espaço de análise das relações fundamentais para o estudo de questões no campo da Museologia.

Os museus do século XXI podem então ser caracterizados como um reflexo de todo esse processo, em que a comunicação com o público torna-se o aspecto principal do propósito de existência dos museus, e as coleções estão completamente vinculadas a tal aspecto, tanto em relação a sua natureza e finalidades, como a forma na qual serão apresentadas.

1 Desde sua criação, estas instituições supranacionais atuaram através da promoção de documentos (cartas, convenções e recomendações) voltadas para a definição e orientação das práticas e gestão museológicas. Estes condicionantes legais têm tipologias diversas, cabendo aqui diferenciar cada uma delas: Cartas são documentos que atuam na definição de conceitos e princípios sobre um determinado assunto, de forma a orientar a prática do interveniente; as Recomendações definem princípios capazes de orientar as políticas particulares de cada Estado no âmbito do patrimônio; por fim, as Convenções atuam no âmbito 
da jurisdição, comprometendo assim os Estados aderentes com vinculação jurídica dos mesmos aos dispositivos constantes nas mesmas.

Bibliografia citada:

Fernandes, Ana Mercedes Stoffel (2007). Gestão $e$ sustentabilidade dos Ecomuseus e museus comunitários. Museus de comunidade: experiências e reflexões para um melhor desempenho. Rio de Janeiro, Brasil: III Encontro de Ecomuseus e Museus Comunitários (2004).

ICOM (1995). Estatutos do ICOM. In. Cadernos de Sociomuseologia no 15 - 1999. Lisboa, Portugal: ULHT.

ICOM. (1984). Declaração de Oaxtepec, México. In. Primo, Judite S. (1999). Pensar Contemporaneamente a Museologia. Lisboa, Portugal: Cadernos de Socio-Museologia 16, ULHT.

ICOM (1992). Declaração de Caracas. In. Cadernos de Sociomuseologia no 15 - 1999. Lisboa, Portugal: ULHT.

ICOM. (1972). Mesa Redonda de Santiago do Chile. In. Cadernos de Sociomuseologia no 15 - 1999. Lisboa, Portugal: ULHT.

UNESCO (1958) Seminário Reginal da UNESCO sobre a Função Educativa dos Museus Rio Janeiro - 1958. Tradução: M. Cristina O. Bruno e M. Pierina F. Camargo. Rio de Janeiro, Brasil.

Varine, Hugues de. (2000) A nova museologia: Ficção ou Realidade. In: Museologia Social. Porto Alegre: Unidade Editorial / Secretaria Municipal de Cultura. 